\title{
Mapping the Complex Phase Formation at the Surface of Supercritical CO2- Reacted Fayalite for Geologic Sequestration of Greenhouse Gases
}

\author{
Daniel E. Perea, Jia Liu, Bruce Arey, Libor Kovarik, Robert Colby, Odeta Qafoku, Theva \\ Thevuthasan, and Andrew R. Felmy \\ Environmental Molecular Sciences Laboratory, Pacific Northwest National Laboratory, \\ Richland, WA 99352
}

Geologic materials have the potential to serve as a m edia for the long-term removal of the greenhouse gas $\mathrm{CO}_{2}$ by the injection of supercritical (sc) $\mathrm{CO}_{2}$ into host rock mineral in deep subsurface formations. During mineral trapping, the $\mathrm{scCO}_{2}$ reacts with the rock mineral to form insoluble secondary mineral carbonates to effectively remove $\mathrm{CO}_{2}$. A specific class of minerals known as Olivines appears to have the highest potential to permanently sequester $\mathrm{CO}_{2}$ by mineral trapping $[1,2]$. Olivines are a class of neosilicates with end members rich in either $\mathrm{Fe}$ (fayalite) or $\mathrm{Mg}$ (forsterite). During reactions with aqueous solutions, fayalite, $(\mathrm{Fe}, \mathrm{Mg})_{2} \mathrm{SiO}_{4}$, dissolution occurs releasing $\mathrm{Fe}$ and $\mathrm{Si}$ which can precipitate with nearby anions to form secondary minerals including hematite, goethite, sulfates, carbonates, and amorphous silica [2]. An atomic-scale understanding of the formation and composition of the secondary phases is largely unknown and precludes a full understanding of the reactions that take place.

In this work, we use a combination of atom probe tomography (APT) and transmission electron microscopy (TEM) to map the atomic-scale composition of both unreacted and $\mathrm{scCO}_{2}$-reacted natural fayalite mineral. The reaction conditions for the water-saturated $\mathrm{scCO}_{2}$-reacted fayalite are described in detail in Ref [2]. Upon the reaction with water-saturated $\mathrm{scCO}_{2}$, precipitates with a plate-like morphology are found to form on the surface of the fayalite as shown in Figure 1a. Energy dispersive $x$-ray spectroscopy $(\mathrm{EDX})$ in Figure $1 \mathrm{~b}$ ) indicates the plate-like features have a ferrite core with a silica shell. A tom probe tomography is being applied to map the composition of both the unreacted and reacted fayalite (Figure 2). In Figure 2 a), a homogenous distribution of $\mathrm{Si}, \mathrm{Fe}$, and $\mathrm{O}$ is observed, along with a homogenous distribution of $\mathrm{Mg}, \mathrm{Mn}$, and $\mathrm{Ca}$ impurities. In contrast, APT analysis of the reacted fayalite reveals an interface between a Fe-rich/Si-rich phase (Figure $2 \mathrm{~b}$ ), with the same $\mathrm{Mg}, \mathrm{Mn}$, and $\mathrm{Ca}$ impurities localized within the Si-rich phase at the interface defined by a $25 \%$ isoconcentration surface. Correlative TEM/APT is being pursued to phase structure and composition in order to understand the formation mechanism of the plate-like precipitates and bring us further to understanding the complex reactions that take place between $\mathrm{scCO}_{2}$ and fayalite for carbon sequestration.

[1] Felmy, A.R., et al., Reaction of water-saturated supercritical CO2 with forsterite: Evidence for magnesite formation at low temperatures. Geochim Cosmochim Ac, 2012. 91: p. 271282.

[2] Qafoku, O., et al., Fayalite dissolution and siderite formation in water-saturated supercritical CO2. Chem Geol, 2012. 332: p. 124-135.

[3] The research was supported through the user program at Environmental Molecular Sciences Laboratory at Pacific Northwest National Laboratory under user proposal\# 39937 

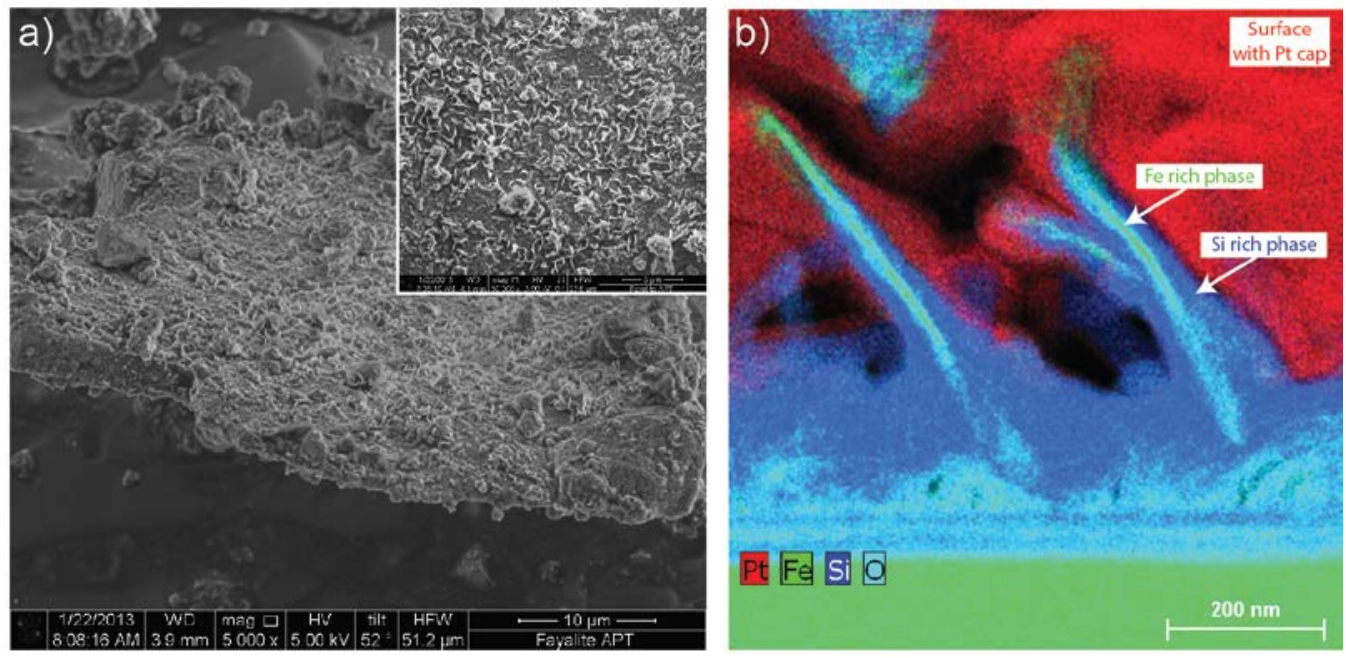

Figure 1. a) SEM image of the surface morphology of $\mathrm{scCO}_{2}$-reacted fayalite; inset is closer view of surface. b) cross-section EDX composition map taken in a TEM of the $\mathrm{scCO}_{2}$-reacted fayalite surface.

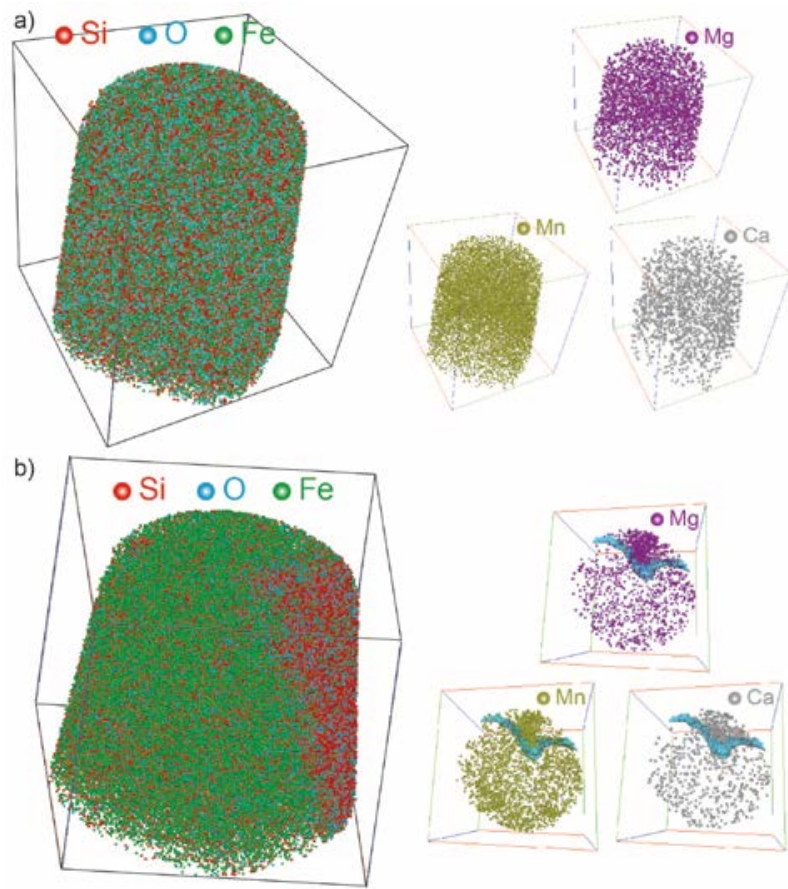

Figure 2. APT reconstruction of natural (a) and reacted (b) fayalite. Impurity distributions are shown to the right. Note in b) the interface between Si-rich/Fe-rich phase; impurities are localized at interface defined by a $25 \% \mathrm{O}$ isoconcentration surface within the in the Si-rich phase. 